\title{
Multiple Crack Growth Prediction in AA2024-T3 Friction Stir Welded Joints, Including Manufacturing Effects
}

\author{
Carlone, Pierpaolo; Citarella, Roberto; Sonne, Mads Rostgaard; Hattel, Jesper Henri
}

Published in:

International Journal of Fatigue

Link to article, DOI:

10.1016/j.ijfatigue.2016.04.004

Publication date:

2016

Document Version

Peer reviewed version

Link back to DTU Orbit

Citation (APA):

Carlone, P., Citarella, R., Sonne, M. R., \& Hattel, J. H. (2016). Multiple Crack Growth Prediction in AA2024-T3 Friction Stir Welded Joints, Including Manufacturing Effects. International Journal of Fatigue, 90, 69-77. https://doi.org/10.1016/j.ijfatigue.2016.04.004

\section{General rights}

Copyright and moral rights for the publications made accessible in the public portal are retained by the authors and/or other copyright owners and it is a condition of accessing publications that users recognise and abide by the legal requirements associated with these rights.

- Users may download and print one copy of any publication from the public portal for the purpose of private study or research.

- You may not further distribute the material or use it for any profit-making activity or commercial gain

- You may freely distribute the URL identifying the publication in the public portal 


\section{Accepted Manuscript}

Multiple Crack Growth Prediction in AA2024-T3 Friction Stir Welded Joints, Including Manufacturing Effects

Pierpaolo Carlone, Roberto Citarella, Mads R. Sonne, Jesper H. Hattel

PII:

$$
\text { S0142-1123(16)30052-4 }
$$

DOI: http://dx.doi.org/10.1016/j.ijfatigue.2016.04.004

Reference: JIJF 3920

To appear in:

$$
\text { International Journal of Fatigue }
$$

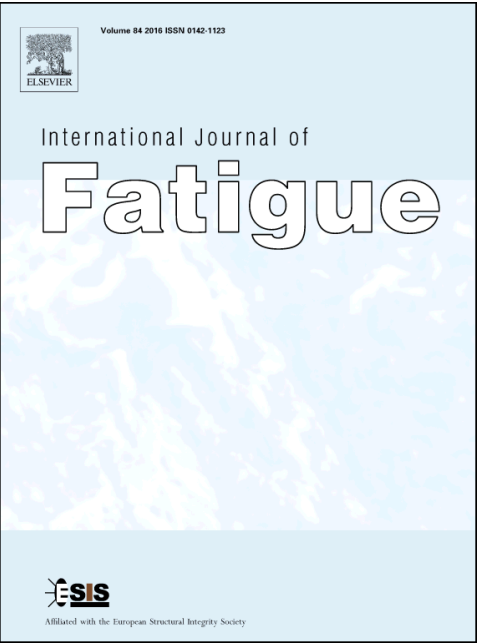

Received Date: $\quad 24$ December 2015

Revised Date: $\quad 5$ April 2016

Accepted Date: $\quad 8$ April 2016

Please cite this article as: Carlone, P., Citarella, R., Sonne, M.R., Hattel, J.H., Multiple Crack Growth Prediction in AA2024-T3 Friction Stir Welded Joints, Including Manufacturing Effects, International Journal of Fatigue (2016), doi: http://dx.doi.org/10.1016/j.ijfatigue.2016.04.004

This is a PDF file of an unedited manuscript that has been accepted for publication. As a service to our customers we are providing this early version of the manuscript. The manuscript will undergo copyediting, typesetting, and review of the resulting proof before it is published in its final form. Please note that during the production process errors may be discovered which could affect the content, and all legal disclaimers that apply to the journal pertain. 


\title{
Multiple Crack Growth Prediction in AA2024-T3 Friction Stir
}

\section{Welded Joints, Including Manufacturing Effects}

\author{
Pierpaolo Carlone ${ }^{1, *}$, Roberto Citarella ${ }^{1}$, Mads R. Sonne ${ }^{2}$, Jesper H. Hattel ${ }^{2}$ \\ ${ }^{1}$ Department of Industrial Engineering, University of Salerno, Via Giovanni Paolo II 132, 84084,
} Fisciano, Italy

${ }^{2}$ Department of Mechanical Engineering, Technical University of Denmark, 2800 Kgs. Lyngby, Denmark

*Corresponding author: pcarlone@unisa.it

\begin{abstract}
A great deal of attention is currently paid by several industries toward the friction stir welding process to realize lightweight structures. Within this aim, the realistic prediction of fatigue behavior of welded assemblies is a key factor. In this work an integrated finite element method - dual boundary element method (FEM-DBEM) procedure, coupling the welding process simulation to the subsequent crack growth assessment, is proposed and applied to simulate multiple crack propagation, with allowance for manufacturing effects. The friction stir butt welding process of the precipitation hardened AA2024-T3 alloy was simulated using a thermo-mechanical FEM model to predict the process induced residual stress field and material softening. The computed stress field was transferred to a DBEM environment and superimposed to the stress field produced by a remote fatigue traction load applied on a notched specimen. The whole procedure was finally tested comparing simulation outcomes with experimental data. The good agreement obtained highlights the predictive capability of the method. The influence of the residual stress distribution on crack growth and the mutual interaction between propagating cracks were analyzed as well.
\end{abstract}

Keywords: Friction Stir Welding, Residual Stress, Crack propagation, FEM, DBEM. 


\section{Introduction}

Friction stir welding (FSW) is a solid state welding technique employed for joining several similar as well as dissimilar materials pairs, generally considered difficult to weld using conventional welding techniques [1-5]. The main benefits provided by FSW over conventional fusion welding processes can be summarized in the reduction of porosity, of microstructure alteration and of process induced residual stresses and distortions. These advantages have made FSW attractive to several industries, such as aeronautical, automotive, and naval, to cite but a few. Even though several issues concerning microstructure effects and stress-strain development in FSW have already been clarified, a deeper understanding of static and fatigue performances of FSW welded assemblies is imperative for their broader application to structural components. Interesting findings on this topic have already been given in the literature, reporting the slower crack propagation in FSW joint with respect to fusion welded joints. This desirable feature was attributed to some manufacturing effects related to microstructure, microhardness, and residual stresses [5-11].

Although residual stresses induced by FSW are less severe as compared to traditional welding techniques $[3,12]$, they are still considered a major driving force for crack propagation in FSW welded structures. The dominant role of residual stresses on crack growth rates in AA2024 FSW joints was explicitly pinpointed by Bussu and Irving [8]. Their experimental analysis also underlined the secondary role played by the local microstructure and microhardness. Similar conclusions were found by Fratini et al. in [7]. Moreover, Dalle Donne et al. emphasized the risk of erroneous prediction of crack propagation in FSW joints, if residual stresses are not properly accounted for [13]. Besel et al. concluded that hardness itself is not the major reason for either fatigue crack nucleation or propagation [14] in FSW joints, whereas they are significantly affected by high residual stress levels in the comparably soft microstructure. Accordingly, Hong et al. discussed the trend of crack propagation behavior in $\mathrm{Al}-\mathrm{Mg}-\mathrm{Si}$ aluminum alloys based on residual stress measurement [15]. In their experimental work, Baragetti and D’Urso [16] also pointed out that AA6060 FSW joints exhibited better fatigue properties if processed at lower feed rate, due to 
the reduction in stress levels. According to Pouget and Reynolds, accurate growth rate predictions can be achieved including residual stress effects into the calculation, however some discrepancies between analytical calculation and experimental findings were attributed to microstructure related closure mechanisms, e.g. oxide-induced closure [17]. A completely opposite conclusion was pointed out by Tra et al., who experimentally investigated the role of residual stresses and microstructure on crack propagation in AA6063-T5 FSW joints [18]. They commented that crack propagation is mainly driven by the inhomogeneous microstructure in and around the welded area, whereas the influence of residual stresses is not so significant. It should be noted, however, that an exceptionally low longitudinal residual stress level was reported in their work (tensile peak $\sim 10$ $\mathrm{MPa}$ ), if compared to similar studies (tensile peak between 60 and $130 \mathrm{MPa}$ ).

Recently, some attempts to numerically assess the fatigue behavior in friction stir welded structures were discussed in literature [19-24]. In [20] an approach based on the Boundary Element Method (BEM) was adopted for crack growth simulation. The initial stress distribution was defined generalizing pointwise experimental measurements. The residual stress redistribution due to crack growth was taken into account and a variable calibration for the crack growth law was provided depending upon the FSW regimes. The same numerical method was employed by some of the authors of the present work to simulate crack propagation in FSW joints, in which the usage of the Dual Boundary Element Method [25] for crack propagation was preferred over other numerical methods to facilitate the remeshing process when considering mixed mode problems. In [21-24] experimentally measured longitudinal residual stress distributions in the cross section were assumed as initial condition. However, the intrinsic difficulties of experimentally obtaining all the components of the residual stress tensor as well as the lack of generality of such a hybrid approach significantly reduce its potential application.

In this paper a numerical investigation on the influence of residual stresses, induced by the friction stir welding process, on fatigue crack growth in aluminum friction stir welded butt joints has been proposed. Due to its wide structural application in the aeronautic and aerospace industries, the 
aluminum alloy AA2024, in the T3 ageing condition, was selected as base material. The computational approach is based on the coupling of the finite element method (FEM) and Dual Boundary Element Method (DBEM). In particular, the thermo-mechanical FEM model, proposed by Sonne et al. in [26], was used to predict the residual stress state in the butt-welded aluminum plates. The computed residual stress field was then superimposed to the stress field produced by a remote fatigue traction load and multiple crack propagation was simulated by the DBEM in an automatic way. The effect of residual stresses on crack growth rates was modeled by the crack growth law adopted in [21-24]. Experimental data were used to validate both FEM and DBEM calculations.

\section{FEM-DBEM Model}

\subsection{Thermo-mechanical FEM model}

In thermo-mechanical modelling of FSW, the most convenient and common assumption, used to reduce the computational complexity of the problem, is to neglect the material flow during welding [27]. This results in semi-coupled thermo-mechanical models in a Lagrangian frame, where the thermal field is calculated prior to the mechanical field by separating the two analyses. A detailed review of computational approaches to FSW simulations is beyond the scope of this work, [28] and [29] can be refereed to for further reading. The model applied in this work was proposed by Sonne et al. [26]. The theoretical basis of this model is briefly explained in this section.

The time-dependent temperature distribution was found by solving the transient heat conduction equation, i.e.

$\rho c_{p} \frac{\partial T}{\partial t}=\frac{\partial T}{\partial x}\left(k \frac{\partial T}{\partial x}\right)+\frac{\partial T}{\partial y}\left(k \frac{\partial T}{\partial y}\right)+\frac{\partial T}{\partial z}\left(k \frac{\partial T}{\partial z}\right)+\dot{Q}_{g e n}^{\prime \prime \prime}$ 
where $\rho$ is the material density, $c_{p}$ is the specific heat capacity, $T$ is the temperature, $k$ is the thermal conductivity and $\dot{Q}_{\text {gen }}^{\prime \prime \prime}$ is the volumetric heat source term. The tool action was modelled by means of a suitable boundary condition applied at the interface between the shoulder and the work piece. A surface heat flux $q$, dependent on the radial position and the local (temperature dependent) yield stress $\sigma_{\text {yield }}$, was imposed at the tool shoulder-adjoining material contact area, without modelling the tool probe, as follows:

$q(r, T)=\left(\frac{2 \pi n}{60}\right) r \frac{\sigma_{y i e l d}}{\sqrt{3}}$

where $n$ is the number of tool revolutions per minute, $r$ is the radial position originating from the tool center, and $\sigma_{\text {yield }}$ is the temperature dependent yield stress [30].

The microstructural evolution of the Al-alloys 2024 in the T3 temper state during FSW has been shown to have a significant effect on the residual stress distribution [26]. In this study, the softening model developed by Myhr and Grong [31] was used to predict the phase transformation during welding. The same approach was also adopted by Richards et al. in [32]. The model relates the fraction of dissolved hardening precipitates $X_{d}$ to the equivalent time of heat treatment, $t_{e q}=t / t^{*}$ (where $\mathrm{t}$ is the period of time at a temperature $T$ and $t^{*}$ is the time for total precipitate dissolution at this temperature) as follows:

$$
\frac{f}{f_{0}}=1-X_{d}=1-t_{e q}^{n}=1-\sqrt{t_{e q}}
$$

$$
t_{e q}=\sum_{i=1}^{N_{\text {total }}} \frac{\Delta t_{i}}{t_{i}^{*}}=\sum_{i=1}^{N_{\text {total }}} \frac{\Delta t_{i}}{t_{\text {ref }} \exp \left[\frac{Q_{\text {eff }}}{R}\left(\frac{1}{T_{i}}-\frac{1}{T_{\text {ref }}}\right)\right]}
$$

where $t_{r e f}$ is the time for total dissolution at the reference temperature $T_{r e f}, \mathrm{R}$ is the universal gas constant and $Q_{\text {eff }}$ is the effective energy for precipitate dissolution. The fraction of hardening 
precipitates $f / f_{0}$ then relates to the equivalent time $t_{e q}$ via the fraction of dissolved precipitates $X_{d}$ as shown in Eq. (3), where $\mathrm{n}$ is a material constant which is obtained experimentally. A value equal to 0.5 is often used, as indicated in the last part of Eq. (3). The yield stress was then predicted via a linear interpolation between the original and the fully dissolved states.

For calculation of the transient as well as the residual stress field in the work piece, a standard mechanical model based on the solution of the three static force equilibrium equations is used, i.e.

$\sigma_{i j, j}+p_{j}=0$

where $p_{j}$ is the body force at any point within the plate and $\sigma_{i j}$ the stress tensor. Hooke's generalized law and linear decomposition of the strain tensor, as well as small strain theory, were applied together with the expression for the thermal strain. The plastic strain evolution is based on the standard $\mathbf{J}_{2}$ flow theory with a temperature dependent von Mises yield surface. According to [26], isotropic hardening behavior is the most suitable for modeling the mechanical behavior of AA2024-T3 when combined with a softening model. The yield stress at the instantaneous temperature was found by interpolation between the upper and lower bound yield stress curves in proportion to $X_{d}$, as follows:

$\sigma_{y}=\left(\sigma_{y_{\max }}-\sigma_{y_{\text {min }}}\right) \frac{f}{f_{0}}+\sigma_{y_{\text {min }}}$

where $\sigma_{\max }$ is the yield stress of the material in the original T3 condition and $\sigma_{\min }$ the yield stress of the fully dissolved material. The upper and lower yield stress curves for AA2024-T3 are available in [26]. The Vickers microhardness (HV) distribution was calculated by adopting the same model as in Eq. (6), obviously replacing yield stress with microhardness values, as follows:

$$
\mathrm{HV}=\left(H V_{\text {max }}-H V_{\text {min }}\right) \frac{f}{f_{0}}+H V_{\text {min }}
$$


using the minimum and maximum hardness values calibrated on the experimental data discussed in [10].

\subsection{DBEM crack propagation model}

The residual stresses present in the main and lateral crack surfaces, stored in the ABAQUS .odb result file, were imported in the commercial suite BEASY [33] for the DBEM crack propagation analysis. An interface routine, already available in the BEASY environment, was employed for this purpose. The propagation was driven by the remote fatigue load and by the superimposed residual stress field (applied on the crack faces). At each step of propagation, new meshed surfaces were automatically added to the previous crack configuration, consistent with the outcomes of the implemented crack growth law. Again the interface routine scanned the odb file to extract the residual stresses to be applied in addition to the residual stresses already exhisting on the previous crack surface. Then the remote load was applied again and a new LEFM analysis was performed in an interative procedure that stopped when a predefined instability crack condition was encountered, i.e. when the stress intensity factor at the crack front reaches a critical value. A flow chart explaining the overall procedure is shown in Fig. 1.

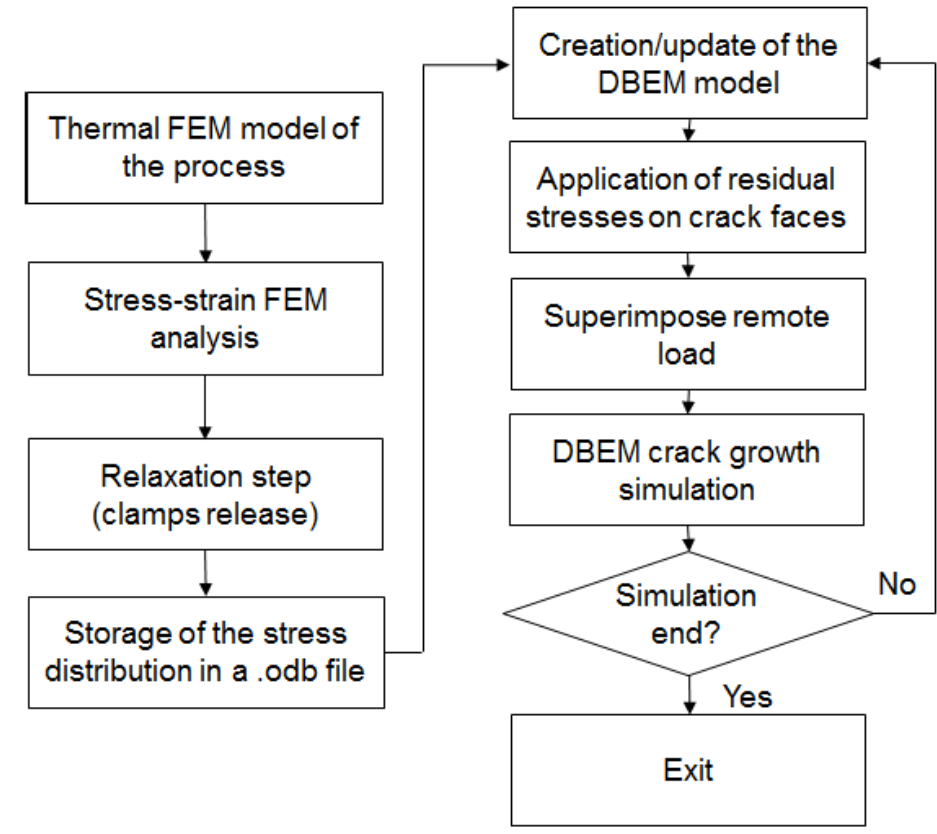


Fig. 1: Flow chart of the implemented FEM-DBEM model.

Residual stresses affect crack propagation since they change the effective value of the total Stress Intensity Factor (SIF) at the crack tip, with both the minimum $\left(K_{\min }\right)$ and the maximum $\left(K_{\max }\right)$ SIF values generally being affected in the same way, leaving the parameter $\Delta K=K_{\max }-K_{\min }$ unchanged. Consequently, the primary effects of residual stresses on crack growth rates are related to the $K_{\max }$ variations rather than to the $\Delta K$ variations. This is accounted for by a two-parameter approach, as described in [34,35]. According to this, fatigue crack growth is promoted by two driving forces, $K_{\max }$ and $\Delta K$. In addition, the procedure assumes that there are two fatigue thresholds, $K_{\text {max, } t h}^{*}$ and $\Delta K^{*}{ }_{t h}$ corresponding to the two driving forces both of which must be simultaneously larger than the relative thresholds for fatigue crack growth to occur. The crack growth law was expressed as follows $[34,35]$ :

$\frac{d a}{d N}=A\left(\Delta K-\Delta K_{t h}^{*}\right)^{n}\left(K_{\max }-K_{\max , t h}^{*}\right)^{m}$

In the present work, Eq. (8) was calibrated by best fitting the material parameters $A, n, m$ based on literature data $[21-24,35]$. The following values were used for the parameters : $\Delta K_{t h}^{*}=1834121$ $\mathrm{N} / \mathrm{m}^{3 / 2}, K_{\text {max }, \text { th }}^{*}=3352014 \mathrm{~N} / \mathrm{m}^{3 / 2}, A=6.745 \mathrm{E}-23 \mathrm{~m}^{1.5^{*(n+m)+1}} / \mathrm{N}^{n+m}, n=1.65, m=0.56$. These parameters are valid for each positive $R$ ratio $\left(\sigma_{\min } / \sigma_{\max }=K_{\min } / K_{\max }>0\right)$. The effects of friction stir welding were emulated by taking into account the residual stress influence on the driving parameters $\Delta \mathrm{K}$ and $\mathrm{K}_{\max }$. Hence, the SIFs used in Eq. (8) were computed as the sum of the SIF corresponding to the remote load and that of the SIF corresponding to process induced residual stresses. In the DBEM analysis, residual stresses were modelled by applying a distribution of tractions on the crack faces corresponding to the residual stresses induced by the welding process.

\subsection{Experimental analysis}


AA2024-T3 aluminum rolled sheets were joined by FSW using a non-consumable Cr-Mo steel tool, adopting an angular tool velocity of $1400 \mathrm{rpm}$ and a welding speed of $70 \mathrm{~mm} / \mathrm{min}$. The tool geometry was characterized by a flat shoulder (20 $\mathrm{mm}$ in diameter) with an unthreaded conical pin (6.2 $\mathrm{mm}$ in major diameter, a cone angle of $30^{\circ}$ and a height of $3.8 \mathrm{~mm}$ ). The forging action of the tool shoulder was enhanced by imposing a tilt angle of $2^{\circ}$. The dimensions of the adjoining sheets were $200 \mathrm{~mm}$ (length), $30 \mathrm{~mm}$ (width), and $4 \mathrm{~mm}$ (thickness). In Fig. 2 the welding setup is shown.

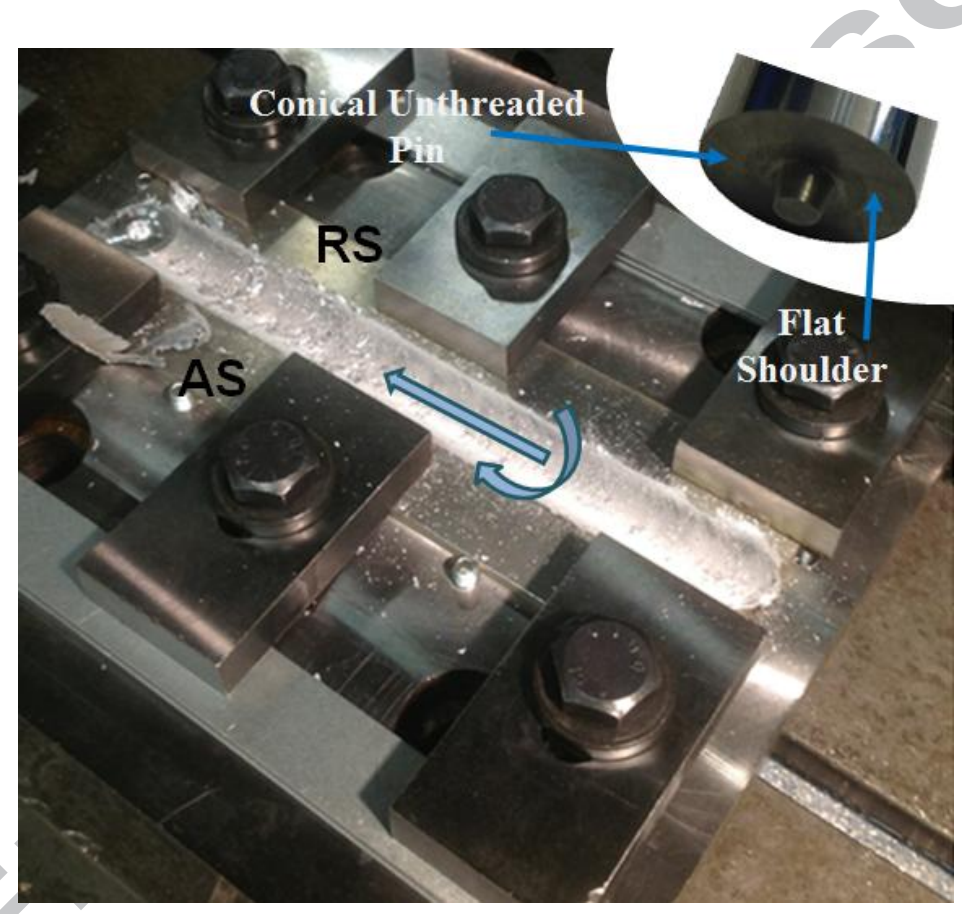

Fig. 2: Welding setup.

The longitudinal residual stress distribution in the generic transverse cross section of the welded joint was obtained by means of the contour method [36]. A more detailed description of this procedure can be found in [37]. The resulting stress field was already used for crack propagation assessment by some of the present authors in [21-24], assuming the repetition of the stress field as computed at the mid-length in each cross section orthogonal to the weld line. However, the outlined hybrid (numerical-experimental) method is obviously quite expensive and not generalizable, since the stress analysis is case specific, calling for a repetition of the procedure for each variation of processing parameters and conditions. What is more, accounting for transient effects and stress 
relaxation in the proximity of the free edges of the sheets was not provided in the crack growth simulations. In that sense, the model in this work represents a generalization of the aforementioned procedure since the residual stresses are now predicted numerically taking the various boundary conditions as well as stress relaxation into account.

The sensitivity of the model with respect to variations in material properties was assessed by comparing the numerically estimated and experimentally measured microhardness along a line orthogonal to the weld line at the mid-thickness of the specimen. Vickers microhardness was measured using an automatic device (LEICA VMHT AUTO) applying the following test parameters: indentation load $100 \mathrm{gf}(0.98 \mathrm{~N})$, loading time $15 \mathrm{~s}$, and indentation speed $60 \mu \mathrm{m} / \mathrm{s}$. The distance between two consecutive indentations was defined as $1 \mathrm{~mm}$. The analysis was performed after 60 days of (post welding) natural ageing to ensure the establishment of a stable microstructure. Crack propagation tests were performed using a universal testing machine INSTRON 8502 with a load cell range equal to $250 \mathrm{kN}$. A fatigue load $\mathrm{P}_{\max }=24 \mathrm{kN}$, corresponding to a remote stress of $\sigma$ $=100 \mathrm{MPa}$, was applied with a frequency equal to $10 \mathrm{~Hz}$ and a load ratio $\mathrm{R}=0.1$, meaning that the stress oscillates between 10 and $100 \mathrm{MPa}$. In order to predefine the crack initiation site, an initial edge notch with a length equal to $2 \mathrm{~mm}$ was realized by wire electro-discharge machining (WEDM) on the retreating side of the weld at the middle length of the specimen [23]. Two crack gages were applied on either side of the notch in order to automatically monitor the advancing crack. Further details concerning the performed crack propagation test are provided in [23,24].

\section{Results and discussion}

\subsection{Welding model validation}

In this paragraph, the capability of the implemented model to predict the mechanical properties and the residual stresses induced by the welding process is assessed by comparison with the experimental data provided by the contour method. The very first part of a proper thermomechanical model is to have a realistic description of the temperature fields before the subsequent 
mechanical analysis. Indeed, temperature gradients are both the direct and indirect sources for stresses because of thermal expansion and metallurgical changes in the aluminum, respectively. Please note that the validation of the temperature calculation procedure was provided elsewhere [38] and is not repeated here for the sake of brevity. The transient temperature field during welding (Fig. 3a), provided by the thermal calculation, was then used in the subsequent stress analysis to obtain the stress state evolution in the welded plate (Fig. 3b). In Fig. $3 b$ the well-known, characteristic lines in compression at the sides of the moving heat source and in tension further behind the moving heat source can be observed as a result of the self-constraining effect played by the colder surrounding material.

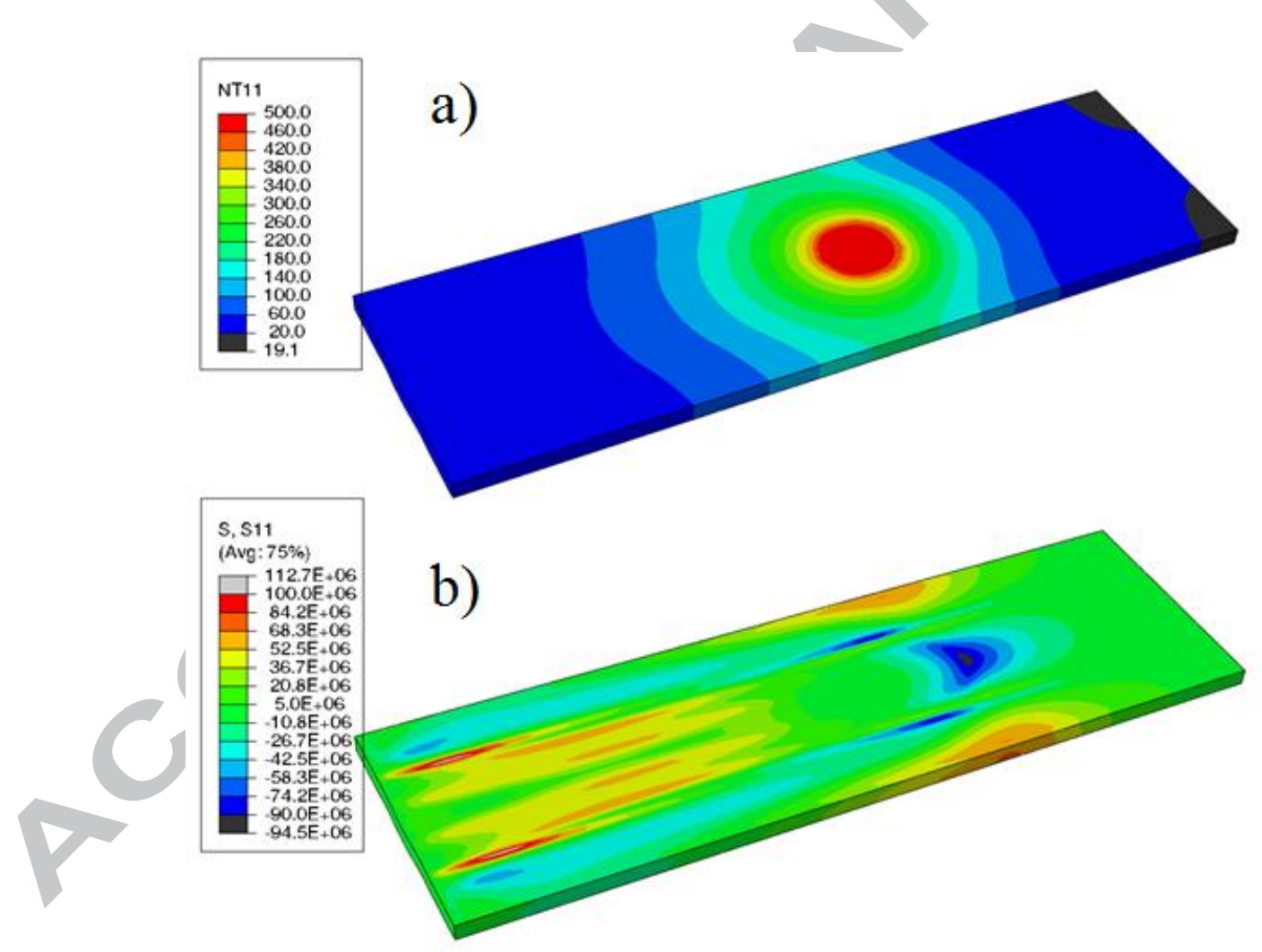

Fig. 3. a) Temperature field $\left({ }^{\circ} \mathrm{C}\right)$ from the heat transfer analysis of welding at $t=100 \mathrm{~s}$. b) The resulting longitudinal stress component $\left(\mathrm{N} / \mathrm{m}^{2}\right)$ from the stress analysis at the same time step.

In the FSW process, heat is generated by the friction between the tool shoulder and the work piece surface, and by the plastic deformation induced in the work piece. The material under and right next 
to the tool is heated up resulting in expansion; however it is partly constrained by the relatively colder material surrounding this region. Subsequently, the material starts yielding in compression and plastic deformation starts to develop. Besides, the thermal gradients due to non-uniform heat generation and the mechanical boundary conditions (i.e. clamping, contact conditions between work piece and the anvil, etc.) also play a significant role for promoting plastic strains and consequently residual stresses $[39,40]$.

The residual stress scenario used for numerical calculations was computed using the same conditions as in the actual process. In particular, the influence of representing the clamping system by proper boundary conditions was assessed by considering different constraining schemes, ranging from a rigid clamping (out of plane displacements completely constrained at the plate-clamp contact areas) to a no clamping condition (preventing only rigid body motion of the model). In between this two extreme cases, an intermediate approach was also explored, based on the consideration of the intrinsic elastic behavior of the clamping bolts as well as of the axial thermal expansion (caused by conductive heat fluxes and heating) experienced by the bolts themselves during the welding process. It should specifically be mentioned that spring elements, aligned along the out of plane direction, were connected to nodes belonging to the virtual plate-clamp contact area to reflect the expected reaction of the clamping system. The numerical predictions were compared with experimental data (see Fig. 4) to identify the most suitable modelling approach for representing the clamping conditions. This is discussed in the following.

First of all we note that the well-known M-shape can be observed in the measured as well as simulated longitudinal residual stresses profiles, meaning that the stresses are lower close to the weld centerline than at the outer shoulder radius of the tool. This finding was irrespective of the applied boundary conditions. However, numerical results also highlighted that applying no mechanical constraints (no clamping case) implied a significant reduction of the computed tensile peaks (approximately 30\% with respect to the experimental value). Accordingly, the compression state further away from the weld line decreased, in absolute value, to enforce overall equilibrium on 
the cross section. On the other hand, some discrepancies in the longitudinal residual stress profile were detected when excessively severe boundary conditions were applied (rigid clamping case). Indeed, the hard constraining of the out of plane displacements of nodes belonging to the virtual plate-clamp contact area enhanced the compression state at the edges of the plates as well as the tensile state in the tool region, providing a better agreement with experimental data as compared to the unclamped case. Nevertheless, unrealistic stress plateaus were introduced in the stress profile at the end of the plate-clamp contact area $( \pm 20 \mathrm{~mm}$ from the weld line), due to the abrupt variation in the degree of freedom. The best predictions were provided using spring elements with element stiffness $\mathrm{K}$ of $2 \mathrm{E} 6 \mathrm{~N} / \mathrm{mm}$ Note that using spring elements with a stiffness of $\mathrm{K}=10 \mathrm{~N} / \mathrm{mm}$ results in a similar stress field as for the unclamped case, this was of course expected. In conclusion, the residual stresses distribution computed introducing spring elements with $\mathrm{K}=2 \mathrm{E} 6 \mathrm{~N} / \mathrm{mm}$ was used for the crack propagation analysis.

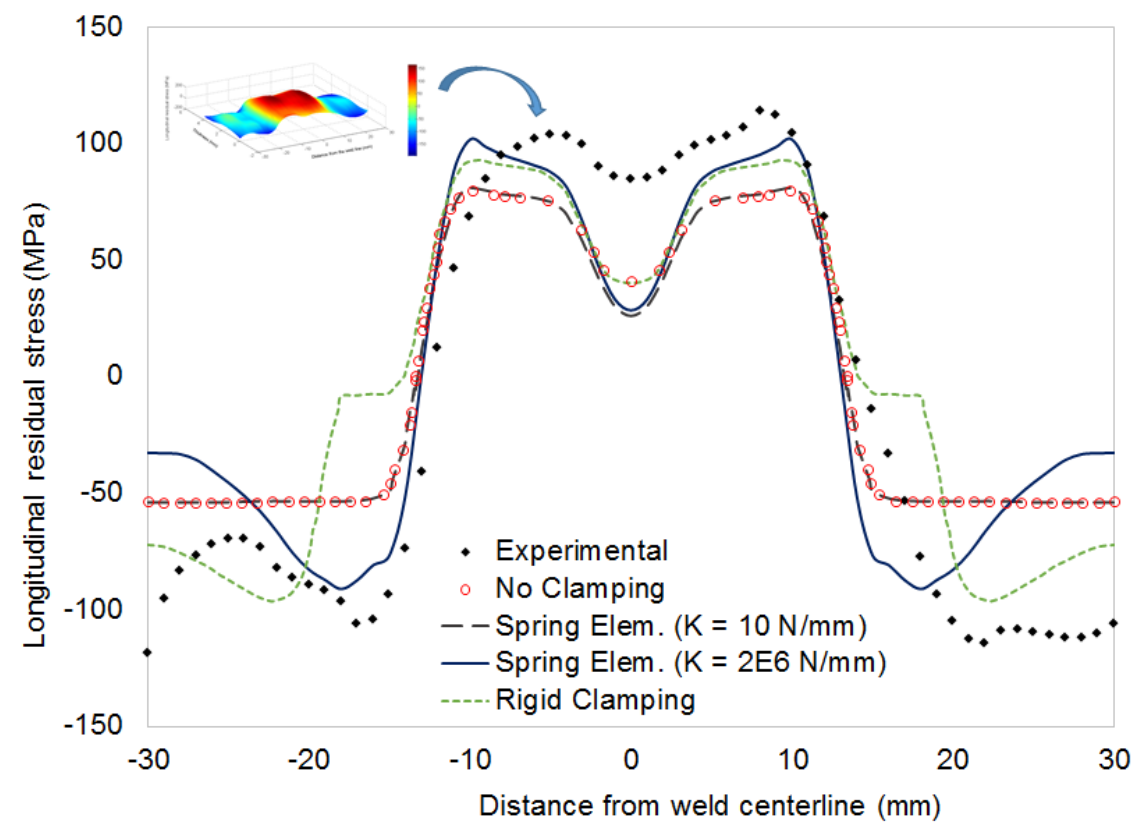

Fig. 4. Comparison of numerical and experimental longitudinal residual stresses.

Numerically obtained and experimentally found microhardness profiles are compared in Figure 5. As seen, a satisfactory agreement was achieved in most of the plate with the main difference being localized in the nugget zone NZ, e.g. in the area close to the weld line. The experimentally found 
HV peak, in the NZ, can be explained by grain refinement and hard compounds precipitation during the natural ageing process. As opposed to this, a continuous microhardness reduction was measured on both sides of the NZ, due to precipitates coarsening and dissolution during the process without a tangible recovery on aging [10,11]. Finally the initial value is restored when approaching the unaffected base material. These are the main mechanisms promoting the enhancement of mechanical properties for the considered material, and hence a similar trend for the yield stress is expected as well. Obviously, since these phenomena are not yet included in the simulation of the process, we expect a discrepancy in the NZ as also seen in Figure 5.

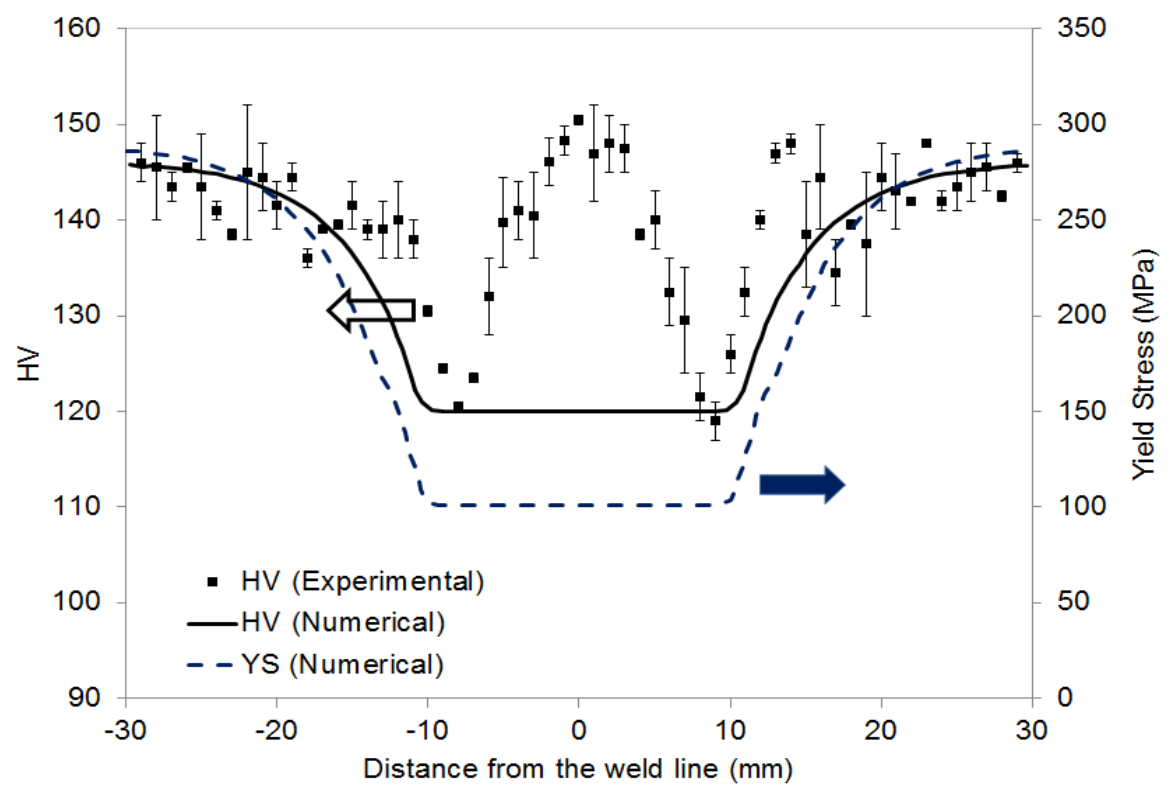

Fig. 5. Micro hardness (numerical and experimental) and yield stress (numerical) profiles

\subsection{Crack propagation}

Experimental tests showed a multiple crack propagation scenario, characterized by the presence of the aforementioned lateral crack (crack 1), initiated from a notch artificially introduced after the welding process by WEDM and of a central semi-elliptic crack (crack 2), spontaneously nucleated in the weld crown due to the surface beach marks left by the tool shoulder. The basic hypothesis, to 
be verified by the simulations, is that, in the initial phase of the fatigue test, the central crack, due to its reduced size and to the distance from the lateral crack, does not significantly influence the propagation of the lateral crack itself, whereas, later on, when the central crack depth becomes comparable to the specimen thickness, the interaction between the two cracks turns out to be nonnegligible, thus calling for an explicit numerical modelling of a multiple crack scenario.

In this context it should be noted that in the experiments reported in [23], the lateral crack, starting from the notch tip, was considered initiated after a pre-cracking phase lasting a number of cycles sufficient to prolong the notch by nucleation of a crack whose superficial length is equal to 0.25 $\mathrm{mm}$. Hence, the initial single crack simulated scenario was based on a lateral through crack with an overall length $(2.25 \mathrm{~mm})$ equal to the sum of notch length $(2 \mathrm{~mm})$ and pre-crack length $(0.25 \mathrm{~mm})$ (Fig. 6). Taking into account that the nucleation time and size for the central crack were not known a priori and considering the absence of experimental evidences indicating, up to this stage, any mutual interaction between the two cracks, the central crack was assumed small and consequently not modelled at all in the considered initial crack propagation phase (Fig. 6).

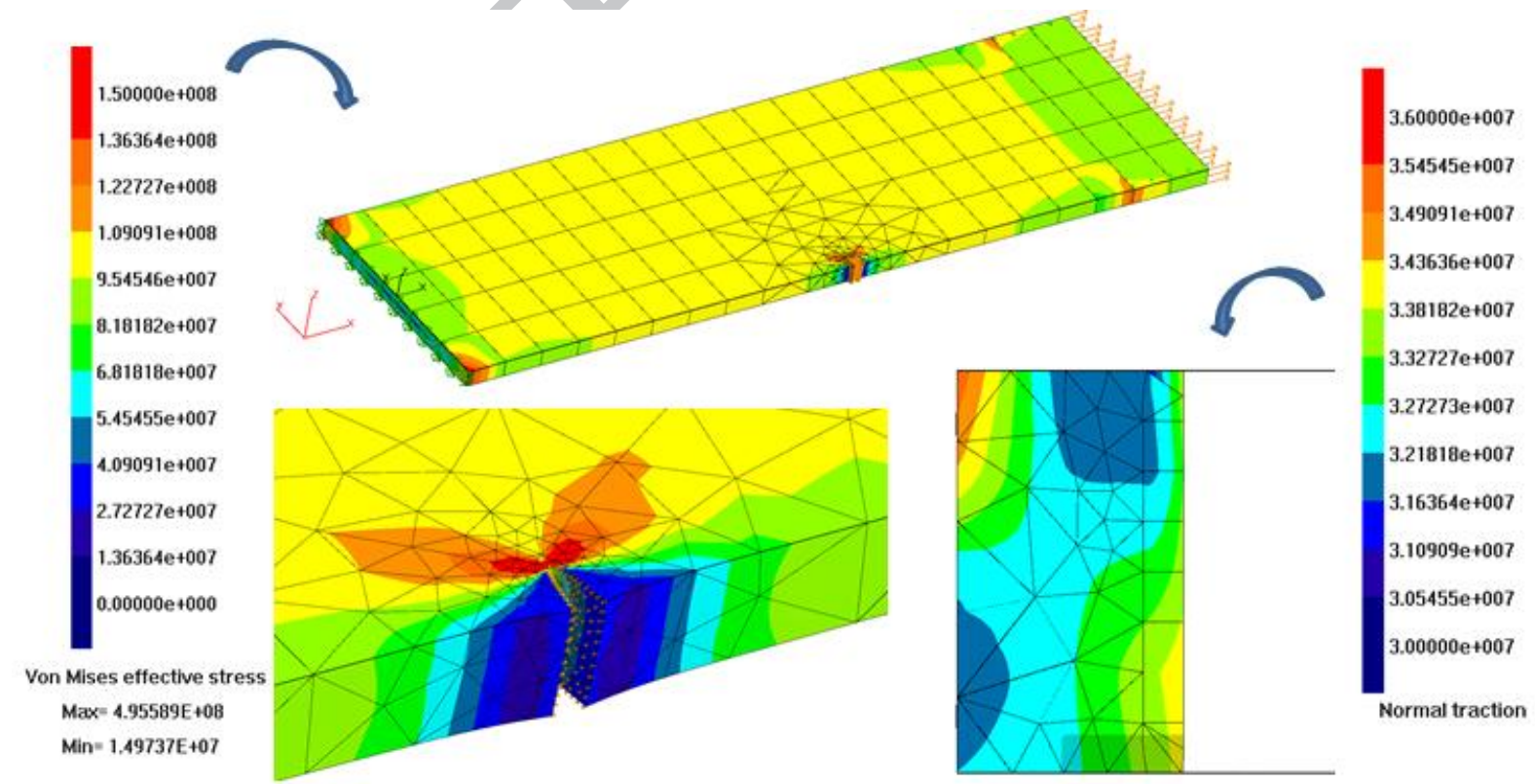

Fig. 6. DBEM initial single crack configuration with highlight of Von Mises stresses (Pa) and normal tractions $(\mathrm{Pa})$ on crack faces (deformation scale $=100)$. 
Consequently, the lateral crack was extended in a single crack propagation simulation, up to $2.5 \mathrm{~mm}$ length, before introducing the second central crack in the model. The timing for the introduction of the central crack in the numerical model was dictated by the following experimental observation: when the lateral crack reached $2.5 \mathrm{~mm}$ in length, it underwent a sudden acceleration, detected and displayed by the applied crack gauges (Fig. 7) [23]. Such behaviour was due to the emerging effect of the central crack that, at this stage, reached an appreciable size. In particular, the initial lateral crack took nearly 10000 simulated fatigue cycles to increase its length from 2.25 to $2.5 \mathrm{~mm}$ (Fig. 7), whereafter the central crack was initiated and therefore included in the multiple crack propagation simulation. The position and shape of such (macroscopic) central crack was suggested by the experimental findings of a post-mortem inspection of the fracture surface, as shown in Fig. 8. The validity of such choice will be supported by the satisfactory matching between the numerical and experimental final scenarios, however it can be a priori justified because the lateral crack alone would had continued its numerical propagation with a much lower growth rate than what was found experimentally, see Fig. 7. Thus, the thumbnail crack propagation was responsible for this sharp acceleration on the lateral crack growth rates exhibited in the numerical simulation and this was consistent with the experimental findings (Fig. 7).

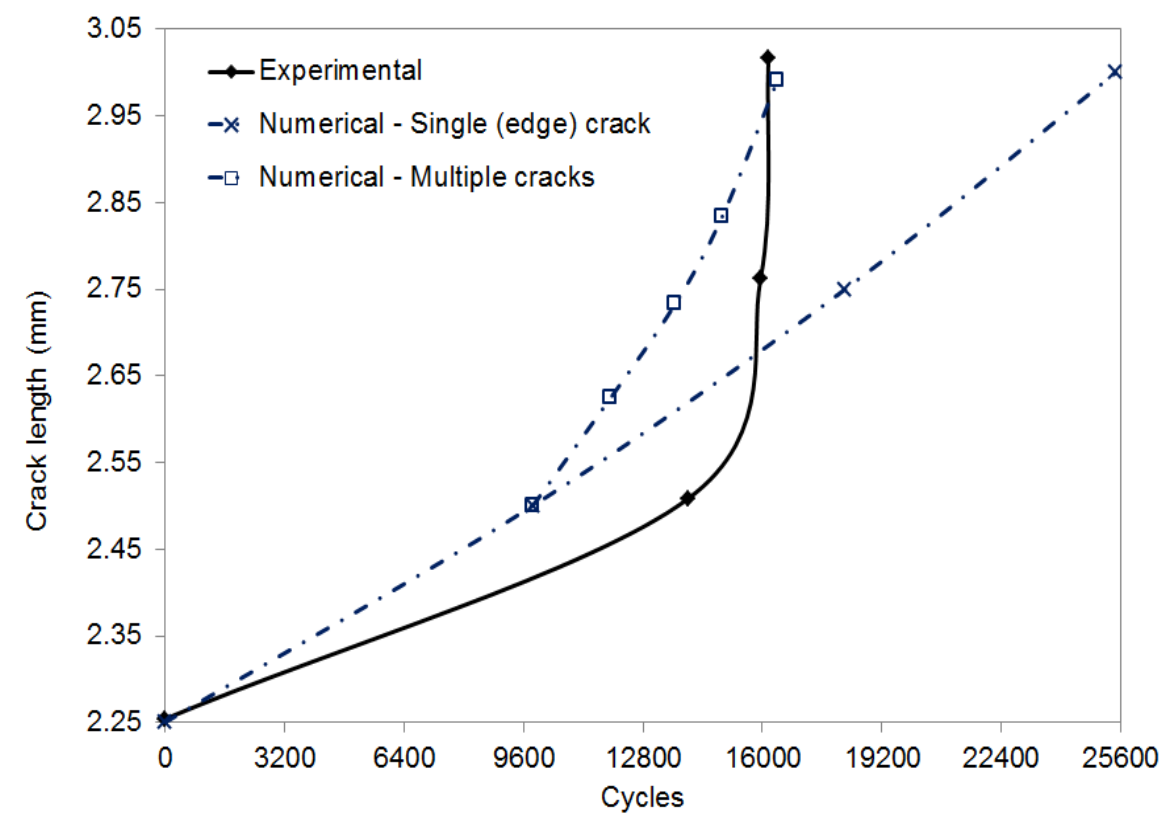


Fig. 7. Lateral crack length, as experimentally monitored and calculated by DBEM, assuming single

(lateral) crack propagation (with no central crack), and multiple crack propagation (considering the introduction of an additional central crack after almost 10000 cycles).

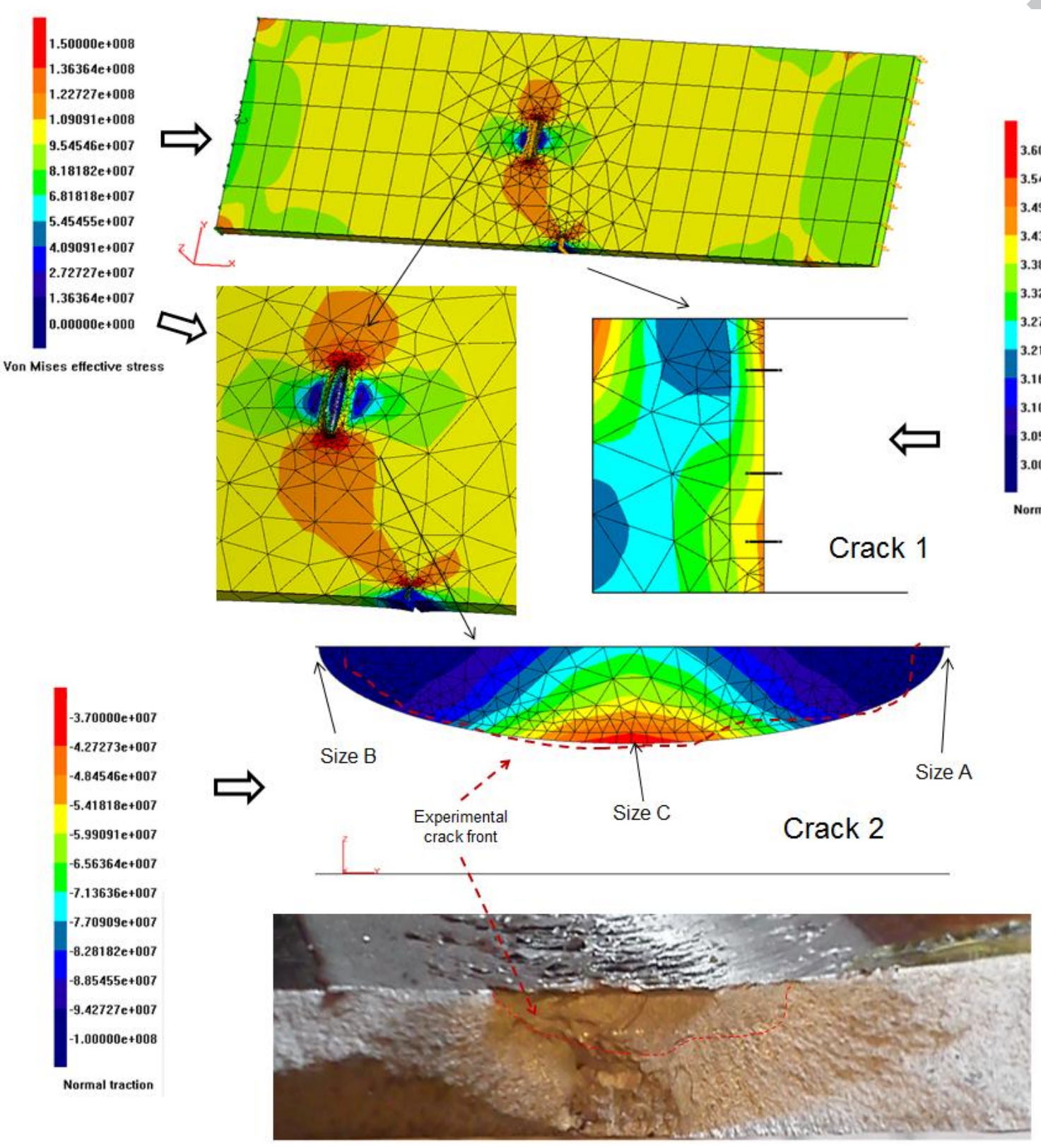

Fig. 8. DBEM initial multiple crack configuration with highlight of Von Mises stresses (Pa), sizing points $(\mathrm{A}, \mathrm{B}, \mathrm{C})$ along the crack front, normal tractions $(\mathrm{Pa})$ on crack faces (deformation scale $=$ 100), and experimental front at central crack initiation (dashed red line). 
After nearly 6550 cycles of multiple crack propagation, subdivided into four crack growth increments, the lateral and central crack reached the sizes shown in Fig. 7 and the thumbnail crack broke through the thickness (Fig. 9), causing the specimen to failure because of fracture instability. As a matter of fact, considering the yield stress profile depicted in Fig. 5, the residual ligament was still not affected by extensive plastic deformation (Fig. 9), excluding the occurrence of a failure due to plastic collapse. The thumbnail crack evolved through the thickness with a symmetric advance (Fig. 9) on both the advancing and retreating sides, consistent with the symmetrically distributed residual stresses.

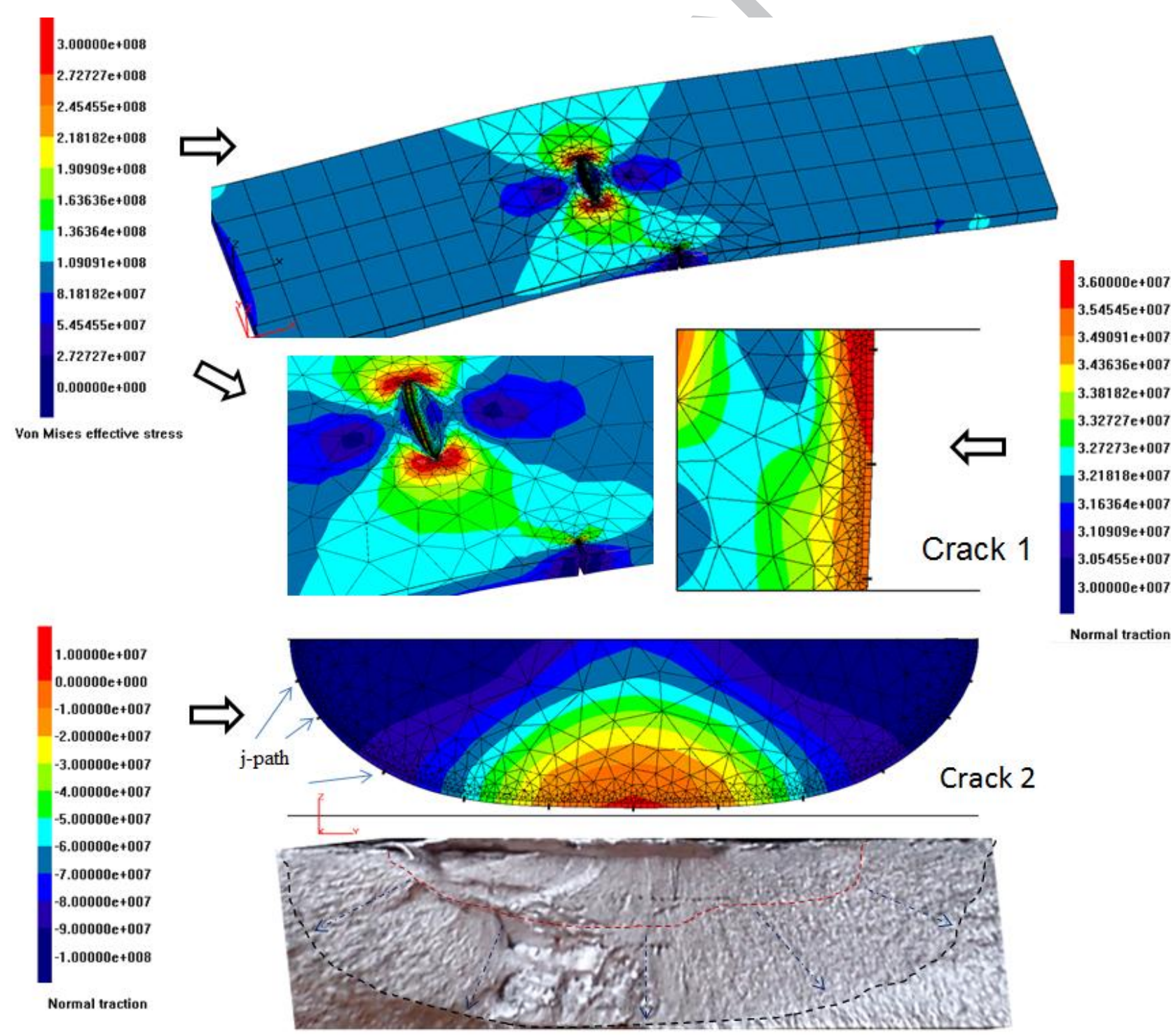

Fig. 9. DBEM final multiple crack configuration with highlight of: Von Mises stresses (Pa), j-path along the crack front, normal tractions (Pa) on crack faces (deformation scale equal to 50), and 
cross comparison between the last numerical central crack scenario and the specimen failure section (the red and black lines indicate the initial modelled crack front and the crack configuration on the verge of ductile rupture, respectively).

The central crack propagation turned out to be responsible for specimen failure, with related $\mathrm{K}_{\mathrm{I}}$ values (mode II and III are almost negligible) approaching the material fracture toughness [19] (as soon as the crack evolves all the way through the thickness a further sharp increase of SIFs along the crack front is expected). On the contrary, SIFs along the lateral crack front, as computed using the J-integral approach [41], were not sufficiently high as compared to the threshold $\left(\mathrm{K}_{\mathrm{maxth}}=3352014 \mathrm{~Pa}^{*} \mathrm{~m}^{0.5}\right)$ to produce appreciable crack advances (Fig. 10).
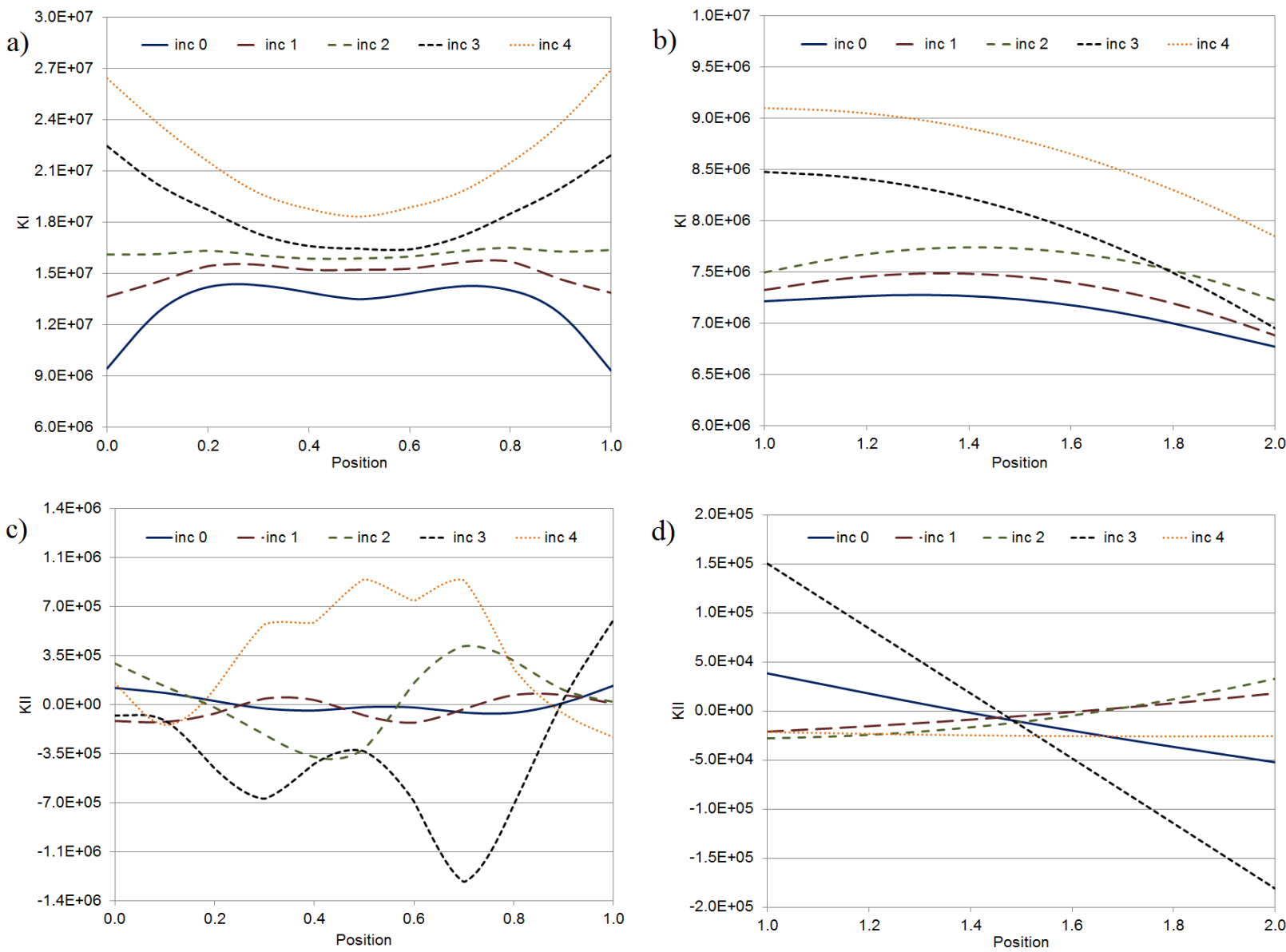
Fig. 10. SIF values $\left(\mathrm{Pa}^{*} \mathrm{~m}^{0.5}\right)$ along the crack fronts of the two cracks for each simulation increment (inc $0 \sim 9850$ cycles; inc $1 \sim 11920$ cycles; inc $2 \sim 13660$ cycles; inc $3 \sim 14920$ cycles; inc $4 \sim$ 16400 cycles;) of crack propagation: the abscissa from 0 to 1 refers to crack 2 (subfigures a and c); the abscissa from 1 to 2 refers to crack 1 (subfigures $b$ and $d$ ).

The final, numerical central crack configuration (Fig. 9) was consistent with the experimental crack scenario at instability [23]. The final crack front exhibited an elliptical shape (as driven by the residual stresses across the thickness and the remote traction load) with a length of the major axis equal to nearly $15.6 \mathrm{~mm}$ (Fig. 11). The specimen failure was forecasted after nearly $9850+6550=16400$ cycles of crack propagation and the central thumbnail crack started to interact with the lateral crack after $355000-16400=338600$ cycles; nearly the same estimate was provided in [23] following a different approach. It is interesting to observe that by a combined use of simulations and available crack gauge recordings it was possible to circumvent the drawback coming from the lack of crack gauge measurements referred to the central crack. As a matter of fact, it was possible to assess the size, after a given number of fatigue cycles, of the crack in the middle of the weld even if no direct measurement was available (there was no expectation of crack initiation in that point before commencing the test and consequently no crack gauges were placed in that area). 


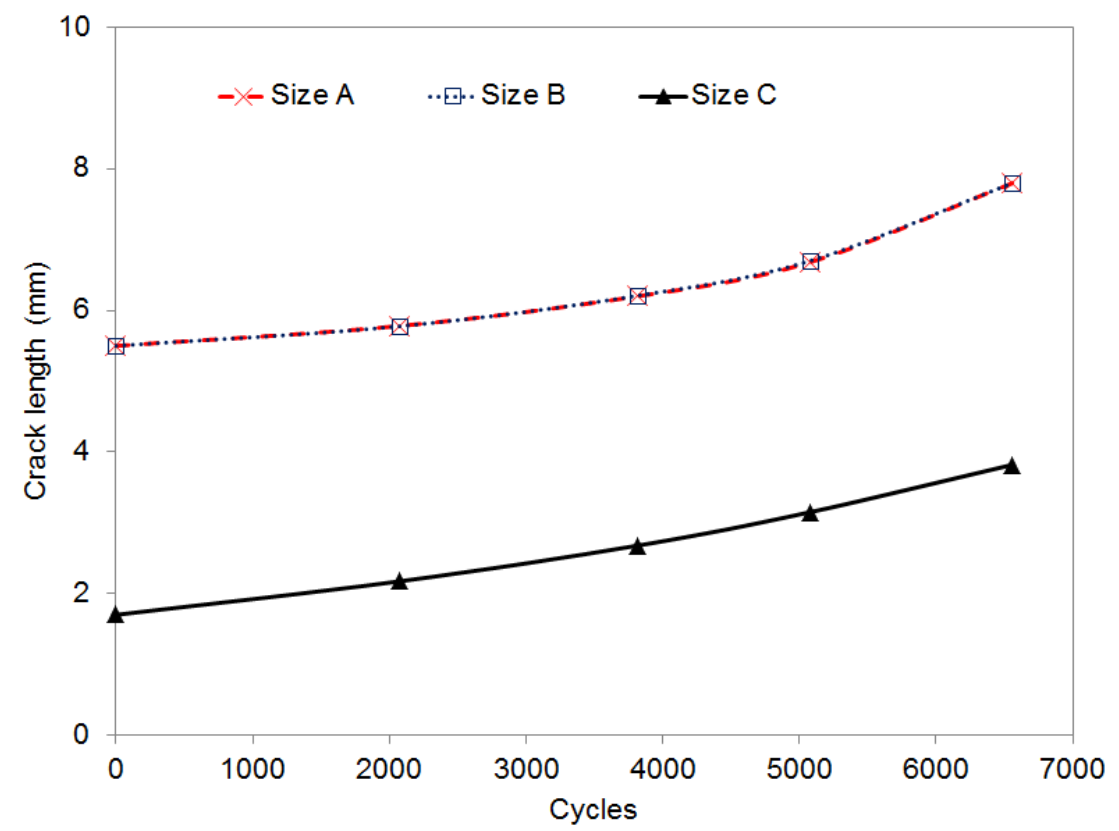

Fig. 11. Crack sizes (mm) for the thumbnail crack (measured at the size points A, B, C) vs. number of cycles.

\section{Conclusions}

The following conclusions can be highlighted:

- the implemented FEM-DBEM approach proved to be able to effectively predict multiple crack growth in the presence of residual stresses induced by the manufacturing process;

- the crack propagation provided by the experimental test, as devised by post mortem metallographic analyses, was characterized by a nearly pure mode I evolution and nearly symmetric shape (with respect to the weld line mid plane). This finding served as a qualitative confirmation of the residual stress field calculated by numerical simulation;

- if the initial crack starts from the weld line the process induced opening stresses have an accelerating effect on the crack propagation;

- by a combined use of simulations and available experimental findings (crack gauge recordings) it is possible to circumvent the drawback coming from the lack of exhaustive experimental data. 
Further development will address the drawback of the need for a unique crack growth law calibration for all the different, simultaneously propagating cracks. More specifically when such cracks are located in different process zones (NZ, thermo-mechanically affected zone, heat affected zone and base material) a variable calibration for the crack growth law would be necessary to improve accuracy.

\section{References}

[1] Rhodes CG, Mahoney MW, Bingel WH, Spurling RA, Bampton CC. Effects of friction stir welding on microstructure of 7075 aluminum. Scripta Mater 1997;36(1):69-75.

[2] Lee CY, Choi DH, Yeon YM, Jung SB. Dissimilar friction stir spot welding of low carbon steel and Al-Mg alloy by formation of IMCs. Sci Technol Weld Joi 2009; 14:216-220.

[3] Carlone P, Palazzo GS. Characterization of TIG and FSW weldings in cast ZE41A magnesium alloy. J Mater Process Technol 2015;215:87-94.

[4] Dressler U, Biallas G, Mercado UA. Friction stir welding of titanium alloy TiAl6V4 to aluminium alloy AA2024-T3, Mater Sci Eng, A 2009;526(1-2):113-117.

[5] Carlone P, Astarita A, Palazzo GS, Paradiso V, Squillace A. Microstructural aspects in Al-Cu dissimilar joining by FSW, Int J Adv Manuf Technol 2015;79:1109-1116.

[6] Moreira PMGP, de Jesus AMP, Ribeiro AS, de Castro PMST. Fatigue crack growth in friction stir welds of 6082-T6 and 6061-T6 aluminium alloys: A comparison, Theor Appl Fract Mec 2008;50:81-91.

[7] Fratini L, Pasta S, Reynolds AP. Fatigue crack growth in 2024-T351 friction stir welded joints: Longitudinal residual stress and microstructural effects, Int J Fatigue 2009;31:495-500.

[8] Bussu G, Irving PE. The role of residual stress and heat affected zone properties on fatigue crack propagation in friction stir welded 2024-T351 aluminum joints, Int J Fatigue 2003;25:77-88.

[9] Tra TH, Okazaki M, Suzuki K. Fatigue crack propagation behavior in friction stir welding of AA6063-T5: Roles of residual stress and microstructure, Int J Fatigue 2012;43:23-29. 
[10] Carlone P, Palazzo G. Influence of process parameters on microstructure and mechanical properties in AA2024-T3 friction stir welding. Metallogr Microstruct Anal 2013;2:213-22.

[11] Genevois C, Fabrègue D, Deschamps A, Poole WJ. On the coupling between precipitation and plastic deformation in relation with friction stir welding of AA2024 T3 aluminium alloy. Mater Sci Eng A Struct 2006;441:39-48.

[12] Kumar N, Mishra RS, Baumann JA. Residual Stresses in Friction Stir Welding, ButterworthHeinemann, 2013.

[13] Dalle Donne C, Biallas G, Ghidini T, Raimbeaux G. Effect of weld imperfection and residual stresses on the fatigue crack propagation in friction stir welded joints, Proceedings of the Second International Conference on Friction Stir Welding, 26-28 June 2000, Gotheburg, Sweden.

[14] Besel M , Besel Y, Mercado UA, Kakiuchi T, Uematsu Y. Fatigue behavior of friction stir welded Al-Mg-Sc alloy. Int J Fatigue 2015;77:1-11.

[15] Hong S, Kim S, Lee CG, Kim S-J. Fatigue crack propagation behavior of friction stir welded Al-Mg-Si alloy. Scripta Mater 2006;55(11):1007-1010

[16] Baragetti S, D’Urso G. Aluminum 6060-T6 friction stir welded butt joints: fatigue resistance with different tools and feed rates, J Mech Sci Technol 2014;28(3):867-877.

[17] Pouget G, Reynolds AP. Residual stress and microstructure effects on fatigue crack growth in AA2050 friction stir welds, Int J Fatigue 2008;30:463-472.

[18] Tra TH, Okazaki M, Suzuki K. Fatigue crack propagation behavior in friction stir welding of AA6063-T5: Roles of residual stress and microstructure, Int J Fatigue 2012;43:23-29.

[19] Živojinović D, Đurđević A, Grbović A, Sedmak A, Rakin M. Numerical Modelling of Crack Propagation in Friction Stir Welded Joint Made of Aluminium Alloy. Proc Mater Sci 2014;3:13301335.

[20] Zadeh M, Ali A, Golestaneh AF, Sahari BB. Three dimensional simulation of fatigue crack growth in friction stir welded joints of 2024-t351 Al alloy, J Sci Ind Res 2009;68:775-82. 
[21] Citarella R, Carlone P, Lepore M, Palazzo GS. Numerical-experimental crack growth analysis in AA2024-T3 FSWed butt joints, Adv Eng Softw 2015;80:47-57.

[22] Carlone P, Citarella R, Lepore M, Palazzo GS. A FEM-DBEM investigation of the influence of process parameters on crack growth in aluminum friction stir welded butt joints. Int J Mater Form 2015;8(4): 591-599.

[23] Citarella R, Carlone P, Sepe R, Lepore M. Hybrid technique to assess the fatigue performance of multiple cracked FSW joints, Eng Fract Mech.

[24] Citarella R, Carlone P, Sepe R, Lepore M. DBEM Crack Propagation in Friction Stir Welded Aluminium Joints, Adv Eng Softw, accepted for publication, DOI

10.1016/j.advengsoft.2015.12.002.

[25] Citarella R, Perrella M. Multiple surface crack propagation: numerical simulations and experimental tests, Fatig Fract Eng Mater Struct 2005;28(1-2):135-148.

[26] Sonne MR, Tutum CC, Hattel JH, Simar A, de Meester B. The effect of hardening laws and thermal softening on modeling residual stresses in FSW of aluminum alloy 2024-T3, J Mater Process Tech 2013;213:477-486.

[27] Hattel JH, Sonne MR, Tutum CC. Modelling residual stresses in friction stir welding of Al alloys - a review of possibilities and future trends, Int J Adv Manuf Technol 2015;76(9):1793-1805. [28] Dialami N, Chiumenti M, Cervera M, Agelet de Saracibar C. Challenges in Thermomechanical Analysis of Friction Stir Welding Processes, Arch Comput Method E, DOI $10.1007 / \mathrm{s} 11831-015-9163-\mathrm{y}$

[29] He X, Gu F, Ball A. A review of numerical analysis of friction stir welding, Prog Mater Sci 2014;65:1-66

[30] Schmidt H, Hattel JH. Thermal modelling of friction stir welding, Scripta Mater 2008;58:332337.

[31] Myhr OR, Grong O. Process modeling applied to 6082-T6 aluminum weldments. Part 1: Reaction kinetics. Part 2: Applications of model, Acta Metal 1991;39:2693-2708. 
[32] Richards DG, Pragnell PB, Williams SW, Withers PJ. Global mechanical tensioning for the management of residual stresses in welds, Mater Sci Eng A 2008;489:351-362.

[33] BEASY V10r14, Documentation, C.M. BEASY Ltd; 2011.

[34] Sadananda K, Vasudevan AK. Short crack growth and internal stresses. Int. J. Fatigue 1997; 19: 99-108.

[35] Citarella R, Cricrì G. A two-parameter model for crack growth simulation by combined FEMDBEM approach, Adv Eng Softw 2009;40:363-373.

[36] Prime MB. Cross-sectional mapping of residual stresses by measuring the surface contour after a cut, J Eng Mater-T 2001;123:162-168.

[37] Carlone P, Palazzo GS. Longitudinal Residual Stress Analysis in AA2024-T3 Friction Stir Welding. Open Mech Eng J 2013;7:18-26.

[38] Sonne MR, Carlone P, Palazzo GS, Hattel JH. Numerical modeling of AA2024-T3 friction stir welding process for residual stress evaluation, including softening effects, Key Eng Mater 2014;611-612:1675-1682.

[39] Richter-Trummer V, Suzano E, Beltrão M, Roos A, dos Santos JF, de Castro PMST. Influence of the FSW clamping force on the final distortion and residual stress field, Mater Sci Eng, A, 2012;538:81-88.

[40] Sonne MR, Carlone P, Citarella R, Hattel JH. Integrated FEM-DBEM simulation of crack propagation in AA2024-T3 FSW butt joints considering manufacturing effects, Key Eng Mater 2015;651-653:877-882.

[41] Rigby RH, Aliabadi MH. Decomposition of the mixed-mode J-integral - revisited. Int J Solids Struct 1998; 35(17): 2073-99. 
Graphical abstract

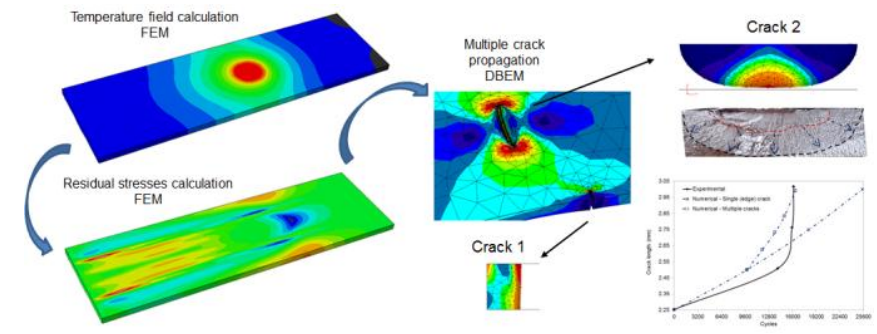




\section{Highlights}

1. Multiple crack propagation in friction stir welded joints is simulated by a finite element method - dual boundary element method approach.

2. Process induced residual stresses and material softening are predicted by finite element analysis.

3. The significant influence of residual stresses on crack growth is demonstrated.

4. Method predictive capability is evidenced by the numerical-experimental agreement. 